\title{
Assessment of reliability, sensitivity, objectivity and validity of MCQ Pharmacology Exams as a potential output variable for predictive analysis
}

\author{
Mariusz Panczyk*, Joanna Gotlib \\ Department of Teaching and Outcomes of Education, Faculty of Health Science, Medical University of Warsaw, Poland
}

\begin{abstract}
Aim: The study aimed to assess the reliability, sensitivity, objectivity and validity of the multiple-choice question (MCQ) Pharmacology Exams conducted between 2009-2014 at the Faculty of Pharmacy, Medical University of Warsaw (MUW), and to analyse the correlations between its results and the chosen criteria of selection of candidates for Pharmacy. Methods: A 6-year retrospective surveillance analysis using the admissions data of candidates for Pharmacy in the years 2005-2010 ( $N=584)$ and multi-stage pharmacology exam results from the years 2009-2014 ( $N=757)$ conducted at the MUW. The analysis of the quality of the MCO Pharmacology Exams conducted in the form of a 100-question test comprised a comparison of parameters of item easiness and discriminating power of particular exam tasks and mean test difficulty of the entire exam. Cranach's $\alpha$ coefficient and Guttman split-half reliability coefficient was estimated to determine the reliability level of the $\mathrm{MCO}$ exams. Results: Reliability of Pharmacology exams estimated with Cronbach's $\alpha$ coefficient (values ranging between 0.786 and 0.884 ) as well as Guttman split-half reliability coefficient (between 0.807 and 0.894 ) showed diversity of internal consistency. The objectivity of assessment of students was analysed with the use of score thresholds, which demonstrated that the "passed/failed" cut-off point was always at the same level. The analysis of correlations between the results of MCO Pharmacology Exams and admission exam showed no systematically occurring correlations between those variables. Conclusion: The analysis of reliability, sensitivity, objectivity and validity of the Pharmacology Exams conducted at the Faculty of Pharmacy, MUW demonstrated that, with all methodological limitations of retrospective studies, the scores of these exams might constitute a good output variable for a predictive assessment.
\end{abstract}

Key words: Performance, Admission, Output variable, Academic Progression, Pharmacy Students, Pharmacy Education.

\section{INTRODUCTION}

An admission policy of university-level schools offering programmes for apothecaries and pharmacists should ensure the selection of the best candidates for this responsible profession. In Poland, beginning with 2005, the admission system for pharmacy is based on the selection of candidates on account of the results of their matura exam -high-school exit exam (equivalent to A-levels in UK, Baccalauréat in France or Abitur in Germany). ${ }^{1}$ Matura results entitle secondary school graduates to apply to one out of 10 Faculties of Pharmacy. ${ }^{2}$ Most medical universities educating future pharmacists require candidates to pass their Matura exam in chemistry and biology at the extended level. Moreover, in 2010 the Medical University of Warsaw (MUW) introduced an additional criterion based on the matura exam in mathematics
Submission Date :24-08-2014 Revision Date : :17-10-2014 Accepted Date :09-12-2014

DOI: 10.5530/ijper.49.1.1 Correspondence Address Mr. Mariusz Panczyk Division of Teaching and Outcomes of Education, Faculty of Health Science, Medical University of Warsaw, Zwirki i Wigury- 61, 02-091 Warsaw, Poland. E-Mail: mariusz.panczyk@ wum.edu.pl

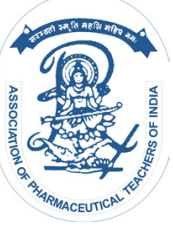

www.ijper.org 
at the basic level. However, the selection of candidates based solely on the "cognitive" criteria is somewhat criticised. ${ }^{3}$ The lack of structured non-cognitive measures does not give certainty with reference to anticipating the potential to develop professional attitudes. The above admission strategy lies between two opposite patterns: the one used in countries admitting all candidates reaching minimal standards with subsequent selection after the first year of studies and the other used in countries applying both cognitive and structured non-cognitive instruments for the selection process. ${ }^{1}$

Over 100 persons graduate from the Faculty of Pharmacy, MUW each year and the number of failures among students does not exceed $15 \%$ of the total. The selection of reliable and valid selection criteria allows for a better assessment whether students shall achieve the assumed outcomes of education and whether graduates shall achieve professional success. The available literature presents a number of publications on assessment of various factors that may influence the effectiveness of studying this major. ${ }^{4-16}$ Different authors most often list the following predictors (explanatory variables): pre-pharmacy GPA (grade point average), ${ }^{11}$ personal interview scores, ${ }^{14}$ California Critical Thinking Skills Test (CCTST), Health Sciences Reasoning Test (HSRT) ${ }^{15}$ and Pharmacy College Admission Test (PCAT) scores. ${ }^{6}$ In order to make the predictive analysis reliable, selected outcome variables should accurately assess this very competence that may account for the success of a Pharmacy student or graduate. The most common output variables in correlation analyses and multiple regression include: academic performance in the first-year of pharmacy school, ${ }^{12}$ GPA for biomedical courses, performance in pharmaceutical science courses, performance in the pharmacotherapy course sequence, GPA in all pharmacy practice and required clerkship courses ${ }^{13}$ and finally North American Pharmacist Licensure Examination (NAPLEX) test. ${ }^{16}$

Pharmacists in Poland are trained on integrated fulltime programmes ${ }^{17}$ that last five and half years, including 10 semesters of studying at university and one additional semester of a compulsory internship in a pharmacy leading to be granted the right to practise the profession (no NAPLEX type final exam). Following the curriculum, students take an exam in pharmacology and pharmacodynamics at the end of the eighth semester. With pharmacokinetic issues, they constitute an essential component of proper understanding of the mechanisms of action of drugs and practical use of medicinal products in pharmacotherapy. Due to the fact that acquiring knowledge and skills in this field is of great importance for development of key competence of prospective pharmacists ${ }^{18}{ }^{\text {it }}$ may be assumed that this might be a good output variable for predictive assessment. Performance in the pharmacology course, ${ }^{13}$ that is reflected by the score obtained on multiple-choice question (MCQ) exam, may be one of the most important methods for assessment of the level of student's preparation for the profession of pharmacist.

The present study aimed to assess the reliability, sensitivity, objectivity and validity of the MCQ Pharmacology Exams conducted between 2009-2014 at the Faculty of Pharmacy, MUW and to analyse the correlations between its results and the chosen criteria of selection of candidates for Pharmacy.

\section{METHODS}

A 6-year retrospective surveillance analysis was performed using the admission data of candidates for Pharmacy in the years 2005-2010 ( $N=584)$ and the results of multi-stage exams in pharmacology in the years 2009-2014 ( $N=757$, mean age for each year: 23.1 $\pm 1.31)$ conducted at the MUW. See Table 1 for details on the study group.

Raw data were preprocessed using TESTY version 7 (Testy komputerowe, Copyright (C) 1994-2014 by Sławomir Zalewski). Information was read in the database, processed in Microsoft Excel 2010 (Microsoft Corporation) and exported to Statistical version 10 (Stat Soft, Inc.) for further analysis. All programs were used in compliance with the MUW license.

The admission data comprised the following: total point score obtained on the admission exam and isolated scores in chemistry and biology, as well as, additionally, in mathematics for the year 2010. The analysis of quality of the Pharmacology Exams conducted in the form of a 100-question test comprised a comparison of parameters of item easiness and discriminating power of particular exam tasks and mean test difficulty of the entire exam. Cronbach's $\alpha$ coefficient (the Kuder-Richardson Formula 20 for a test comprising dichotomous variables) $^{19}$ and Guttman split-half reliability coefficient were estimated to determine the reliability level of tests. $^{20}$

Normal distribution parameters of particular pharmacology exam results were assessed using the ShapiroWilk test and data were screened for outliers using Grubbs test. The equivalence of particular editions of the exam was estimated with a comparison of medians with the Mann-Whitney U test or comparison of means with Student's t-test, depending on meeting the conditions. Cohen's $d$ was used to estimate the effect size of difference. $^{21}$

One-way analysis of variance ANOVA and post-hoc RIR Tukey honestly significant difference test were used to 
assess the discriminatory capacity of the pool of questions in particular pharmacology exams. The analysis was preceded by Levene's test for homogeneity of variances. The Kruskal-Wallis one-way analysis of variance test and post-hoc multiple comparisons of mean ranks were used to compare score requirements for particular grades on the pharmacology exam.

Pearson's $r$ linear correlation coefficient was used to assess the strength of the correlation between the score obtained by a student on the admission exam and the score on the pharmacology exam. The correlation analysis was also performed for the results in thematic subgroups: chemistry and biology (years 2005-2010) as well as mathematics (only for the 2010 year).

For all analyses, the a priori level of significance was established at 0.05 .

\section{RESULTS}

The analysis of particular pharmacology exam editions by nature of distribution of this variable showed a nearly normal distribution with a slight deviation from symmetry (slight skewness) in most cases. Furthermore, particular editions of the MCQ exams did not differ significantly with respect to the scope of variability of the results. The comparative analysis of both exam varieties in each year of the study demonstrated the maintenance of equivalence. All effect sizes were less than 0.20 , the value below which it is commonly considered to indicate a negligible effect. See Table 2 for a list of all results.

Reliability of Pharmacology exams estimated with Cronbach's $\alpha$ coefficient (values ranging between 0.786 and 0.884 ) as well as Guttman split-half reliability coefficient (between 0.807 and 0.894 ) showed diversity of internal consistency. A detailed evaluation of the test scores allowed for the selection of test questions with a negative correlation, i.e. significantly decreasing the reliability of the exam. With these questions excluded from the exam set, the overall reliability of tests, measured with Cronbach's $\alpha$, has increased (Table 3).
A detailed analysis of quality parameters of particular questions in pharmacology allowed for an assessment of the level of difficulty and discriminating power of exam tasks in subsequent years. Although the index of test difficulty was slightly different for particular exams (values ranging between 0.59 and 0.65 ), no statistically significant difference was found in the mean values of item easiness of the pool of questions for subsequent years (analysis of variance, $\mathrm{P}>0.05$ ). A comparison of discriminating power of the exam questions demonstrated significant differences (analysis of variance, $\mathrm{P}<0.01)$. The analysis with post-hoc RIR Tukey honestly significant difference test showed that the mean discriminating power of the questions in the 2014 exam was significantly greater compared to those used in the preceding years.

Due to the fact that the course grade ranging between 2 and $5(2,3,3.5,4,4.5,5)$ constituted the final result of pharmacology exam, score requirements for particular grades were compared. Figure 1 show that only in 2013 score thresholds were lowered for all grades, except for the "passed/failed" cut-off point (discrimination between grades 2 and 3). The point range and degree of diversification of scores within particular grades were constant in the remaining exam editions. See Table 4 for detailed comparative analysis of the grading scale.

The analysis of correlations between the score obtained by students on pharmacology exam and results of the entrance exam for Pharmacy demonstrated no significant correlations between the variables for the 2011 and 2012 years. Among the remaining years, positive correlations were observed for the results in chemistry (2009, 2010, and 2013) and biology (2013 and 2014), but they were not strongly correlated (Pearson's $r<0.35$ ). The sum of ranking points also correlated with the pharmacology exam results in the following three editions: the 2009, 2013 and 2014 years. Positive correlations between the results of the pharmacology exam and all selection criteria for Pharmacy candidates were observed only in 2013. See Table 5 for the results of correlation analysis.

\begin{tabular}{|c|c|c|c|c|c|c|c|c|}
\hline \multicolumn{4}{|c|}{ Admission Exam } & \multicolumn{5}{|c|}{ Pharmacology Exam } \\
\hline Year & $\begin{array}{l}\text { Women } \\
\boldsymbol{N}(\%)\end{array}$ & $\begin{array}{l}\text { Men } \\
N(\%)\end{array}$ & Total $N$ & Year & $\begin{array}{l}\text { Women } \\
\boldsymbol{N}(\%)\end{array}$ & $\begin{array}{l}\text { Men } \\
N(\%)\end{array}$ & Total $\mathbf{N}$ & $\begin{array}{l}\text { Mean age } \\
\pm S D\end{array}$ \\
\hline 2005 & $80(73.4 \%)$ & $29(26.6 \%)$ & 109 & 2009 & 124 (76.5\%) & $38(23.5 \%)$ & 162 & $23.1 \pm 0.38$ \\
\hline 2006 & $91(85.1 \%)$ & $16(14.9 \%)$ & 107 & 2010 & 107 (86.3\%) & 17 (13.7\%) & 124 & $23.4 \pm 2.95$ \\
\hline 2007 & $59(75.6 \%)$ & $19(24.4 \%)$ & 78 & 2011 & $100(80.0 \%)$ & $25(20.0 \%)$ & 125 & $23.0 \pm 0.28$ \\
\hline 2008 & $81(85.3 \%)$ & $14(14.7 \%)$ & 95 & 2012 & 95 (80.5\%) & $23(19.5 \%)$ & 118 & $23.2 \pm 0.53$ \\
\hline 2009 & $71(76.3 \%)$ & $22(23.7 \%)$ & 93 & 2013 & 81 (75.7\%) & $26(24.3 \%)$ & 107 & $23.0 \pm 0.36$ \\
\hline 2010 & $90(88.2 \%)$ & $12(11.8 \%)$ & 102 & 2014 & $106(87.6 \%)$ & $15(12.4 \%)$ & 121 & $23.0 \pm 0.17$ \\
\hline TOTAL & $472(80.8 \%)$ & $112(19.2 \%)$ & 584 & TOTAL & $613(81.0 \%)$ & $144(19.0 \%)$ & 757 & $23.1 \pm 1.31$ \\
\hline
\end{tabular}




\begin{tabular}{|c|c|c|c|c|c|c|}
\hline Year & 2009 & 2010 & 2011 & 2012 & 2013 & 2014 \\
\hline $\begin{array}{l}\text { Number of } \\
\text { questions }\end{array}$ & 100 & 100 & 100 & 99 & 100 & 100 \\
\hline Number of options & 5 & 5 & 5 & 5 & 5 & 5 \\
\hline Number of varieties & 2 & 2 & 2 & 2 & 2 & 2 \\
\hline $\begin{array}{l}\text { Equivalent varieties } \\
\text { (effect size) }\end{array}$ & $\begin{array}{l}P>0.05^{\wedge} \\
(0.04)^{\wedge \wedge}\end{array}$ & $\begin{array}{l}P>0.05^{\wedge} \\
(0.02)^{\wedge \wedge}\end{array}$ & $\begin{array}{l}P>0.05^{\wedge} \\
(0.02)^{\wedge \wedge}\end{array}$ & $P>0.05^{*}$ & $P>0.05^{*}$ & $\begin{array}{l}P>0.05^{\wedge} \\
(0.20)^{\wedge \wedge}\end{array}$ \\
\hline $\begin{array}{l}\text { Normal } \\
\text { distribution** }\end{array}$ & $P>0.05$ & $P>0.05$ & $P>0.05$ & $P<0.05$ & $P<0.05$ & $P<0.05$ \\
\hline Data outliers ${ }^{* * *}$ & $P>0.05$ & $P>0.05$ & $P>0.05$ & $P>0.05$ & $P>0.05$ & $P>0.05$ \\
\hline Mean $(95 \% \mathrm{Cl})$ & $\begin{array}{c}61.9 \\
(60.3-63.4)\end{array}$ & $\begin{array}{c}65.0 \\
(63.4-66.6)\end{array}$ & $\begin{array}{c}59.7 \\
(57.9-61.5)\end{array}$ & $\begin{array}{c}63.4 \\
(61.6-65.2)\end{array}$ & $\begin{array}{c}59.0 \\
(57.1-60.9)\end{array}$ & $\begin{array}{c}64.9 \\
(62.6-67.1)\end{array}$ \\
\hline SEM & 0.810 & 0.808 & 0.909 & 0.914 & 0.950 & 1.128 \\
\hline Median & 63.0 & 66.0 & 59.0 & 65.0 & 60.0 & 65.0 \\
\hline Range of scores & $35.0-87.0$ & $45.0-85.0$ & {$[39.0,18,86.0]$} & $33.0-84.0$ & $26.0-77.0$ & $28.0-90.0$ \\
\hline Q1 - Q3 & $55.0-68.0$ & $60.0-71.0$ & $54.0-66.0$ & $58.0-70.0$ & $52.0-66.0$ & $57.0-74.0$ \\
\hline SD $(95 \% \mathrm{Cl})$ & $\begin{array}{c}10.30 \\
(9.29-11.57)\end{array}$ & $\begin{array}{c}9.00 \\
(8.00-10.29)\end{array}$ & $\begin{array}{c}10.16 \\
(9.04-11.60)\end{array}$ & $\begin{array}{c}9.93 \\
(8.80-11.39)\end{array}$ & $\begin{array}{c}9.82 \\
(8.66-11.35)\end{array}$ & $\begin{array}{c}12.41 \\
(11.02-14.21)\end{array}$ \\
\hline CV & $16.66 \%$ & $13.84 \%$ & $17.01 \%$ & $15.66 \%$ & $16.64 \%$ & $19.13 \%$ \\
\hline Curtosis & 0.046 & -0.389 & -0.083 & 1.031 & 0.442 & 0.275 \\
\hline Skewness & -0.017 & -0.193 & 0.125 & -0.806 & -0.686 & -0.494 \\
\hline
\end{tabular}

$\wedge$ Student's t-test (for $\mathrm{P}<0.05$ varieties are not equivalent) : ^^ Effect size - based on mean differences between samples in terms of standard deviation units (Cohen's d) : * Mann-Whitney $U$ test(for $\mathrm{P}<0.05$ varieties are not equivalent) : ** Shapiro-Wilk test (for $\mathrm{P}<0.05$ distribution is not normal) : *** Grubbs test for outliers (for $\mathrm{P}<$ 0.05 presence of outliers) : $\mathrm{Cl}$ - confidence interval; SEM - standard error of the mean; $\mathrm{Q}_{1}$ - first quartile; $\mathrm{Q}_{3}$ - third quartile; SD - standard deviation; CV - coefficient of variation

\begin{tabular}{|c|c|c|c|c|c|c|}
\hline Year & 2009 & 2010 & 2011 & 2012 & 2013 & 2014 \\
\hline $\begin{array}{l}\text { Guttman split-half reliability } \\
\text { coefficient }\end{array}$ & 0.807 & 0.821 & 0.809 & 0.873 & 0.851 & 0.894 \\
\hline Cronbach's $\alpha$ & 0.821 & 0.786 & 0.827 & 0.828 & 0.818 & 0.884 \\
\hline $\begin{array}{l}\text { Number of questions needed to } \\
\text { achieve } \alpha=0.85^{*}\end{array}$ & 124 & 154 & 118 & 116 & 126 & 74 \\
\hline $\begin{array}{l}\text { Number of questions with negative } \\
\text { correlation }\end{array}$ & 8 & 8 & 6 & 9 & 11 & 3 \\
\hline Cronbach's $\alpha$ after optimization & 0.843 & 0.805 & 0.845 & 0.848 & 0.845 & 0.888 \\
\hline Index of test difficulty & 0.62 & 0.65 & 0.60 & 0.64 & 0.59 & 0.65 \\
\hline Average power discriminating & 0.233 & 0.209 & 0.238 & 0.245 & 0.234 & 0.283 \\
\hline
\end{tabular}

* calculated using the Spearman-Brown prediction formula

\section{DISCUSSION}

Predictive studies on the effectiveness of the admission procedure for Pharmacy candidates are usually based on correlation analyses and regression models. ${ }^{4-16}$ However, these studies shall not be reliable without verified output variables. Reliability (how is it measured?), sensitivity, objectivity, and validity (what is measured?) constitute important components of a comprehensive assessment of tools used for educational measurement.

Various analytical methods may be applied to assess whether a particular assessment tool (such as an exam test) is reliable. Estimating the degree of correlation between the scores in particular parts of a test (e.g. oddeven or split-half reliability ${ }^{20}$ and assessing internal consistency of the results using the assessment of average variances of all exam tasks (Cronbach's $\alpha$-coefficient the Kuder-Richardson Formula 20 for a test comprising dichotomous variables) are most frequently applied. ${ }^{19}$ Cronbach's $\alpha$ yields a reliability estimate of internal consistency by examining the homogeneity of the questions within a test based on the number of items in the test, standard deviation of the total score, and proportion of candidates answering each item correctly. ${ }^{22}$ In the subsequent exam editions, reliability amounted to $\approx 0.8$ (Cronbach's $\alpha$ ), which, according to criteria commonly 


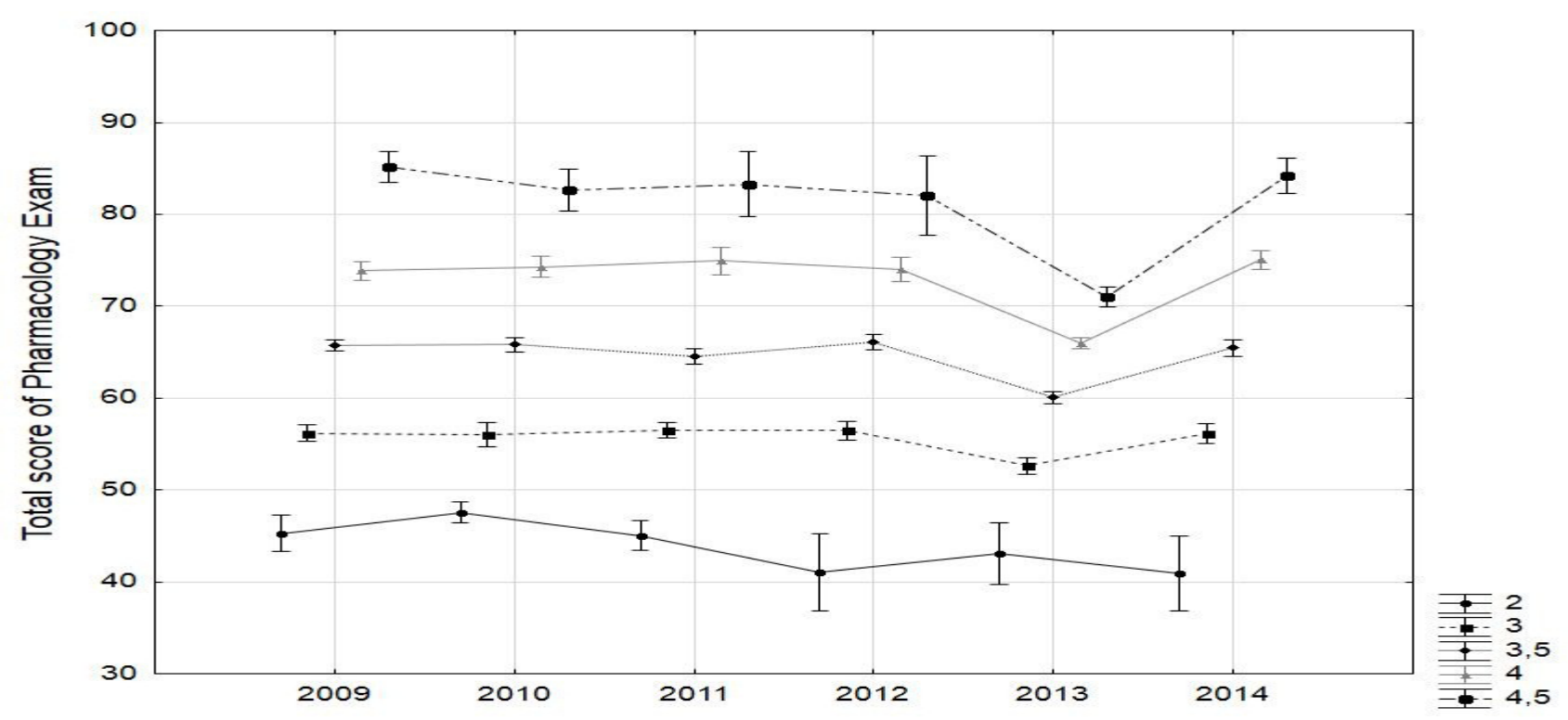

Figure 1: Diagram for mean scores necessary to receive a particular grade that was given on the basis of pharmacology exam results (vertical columns show $95 \%$ confidence intervals for mean). Due to a small number of students with a 5 , the analysis omits these data.

accepted, is enough to evaluate individual differences between candidates. ${ }^{23}$ The assessment with Guttman split-half reliability coefficient that measures correlations between both halves of a test, also produced values greater than 0.8 . In order to select test halves, a random sampling of 50 questions was performed using stratification that involved dividing the pool of questions into thematic areas, distinguished in accordance with the test content outlines. It needs to be emphasised that it is important to obtain high values of the reliability coefficient (higher than 0.9) if it is necessary to perform differentiation inside general results, e.g. when we need to compare achievements of candidates within different thematic areas or fields of a particular subject (so called subtests). An improvement of reliability of the MCQ exam may be achieved by extending a measurement scale. Calculations with Spearman-Brown prophecy formula showed that an increase in reliability of measurement may be achieved by adding more questions to the pool. Obviously, seeking exclusively high values of Cronbach's and Guttman's coefficients does not guarantee exam reliability, since high values of these coefficients only minimize the impact of random errors on the results and do not guarantee the lack of systematic errors that might be even serious. ${ }^{24}$

Apart from the reliability coefficient, a standard error of the mean (SEM) is also an essential parameter for assessment of tools used for educational measurement. SEM represents an estimate of the possible amount of error present in a test score, or the variability of candidate's scores if tested repeatedly with the same test. ${ }^{22}$ Measurement theoreticians (among them Robert L. Brennan) have emphasised that a standard error of measurement is less dependent on the study population compared to a reliability coefficient. ${ }^{25}$ Low value of SEM $(<1.0)$ allowed for an assumption that the pharmacology tests produced very precise assessment. This was indicated by narrow $(95 \%)$ confidence intervals for the mean and standard deviation in subsequent editions of the MCQ exams.

Sensitivity, understood as a capacity of a particular tool to find even the smallest differences between the study parameters, is an important feature of exam tests that needs to be evaluated. ${ }^{26}$ An MCQ exam should have high discriminatory capacity measured with discriminating power. In the literature, questions with high discriminatory capacity are referred to as "burst tasks" 27 since they cause the flatness of the distribution of results (curtosis $<0$ ), which facilitates discrimination and grading. Discriminating capacity with the MCQs is also associated with the item easiness parameter. Questions from opposite categories (very difficult and very easy) are characterised by low discriminating power, occasionally even negative. It needs to be emphasised that a large number of easy and approving questions that require only confirmation of correctness of given information (e.g. the use of "all of the above" (AOTA) and "none of the above" (NOTA) as options) is intellectually less demanding and contributes to obtaining better scores. ${ }^{28}$ Therefore, a proper selection of questions with reference to item easiness and differentiating power needs to be assured during the test making process. The comparison of the above qualitative parameters for subsequent editions of pharmacology exam showed that the mean values of differentiating power of questions was higher than 0.2 (for the 2014 exam it was significantly 


\begin{tabular}{|c|c|c|c|c|c|c|c|}
\hline Year & 2009 & 2010 & 2011 & 2012 & 2013 & 2014 & $P^{*}$ \\
\hline Grade 2 & & & & & & & $>0.05$ \\
\hline $\mathbf{N}$ & 22 & 9 & 24 & 10 & 17 & 13 & \\
\hline Mean & 45.3 & 47.6 & 45.0 & 41.0 & 43.1 & 40.9 & \\
\hline SD & 4.55 & 1.51 & 3.82 & 5.83 & 6.52 & 6.70 & \\
\hline Median & 46.0 & 48.0 & 46.5 & 42.0 & 46.0 & 41.0 & \\
\hline Upper limit & 50.0 & 50.0 & 50.0 & 48.0 & 49.0 & 48.0 & \\
\hline CV & $10.05 \%$ & $3.17 \%$ & $8.47 \%$ & $14.22 \%$ & $15.15 \%$ & $16.38 \%$ & \\
\hline Grade 3 & & & & & & & $<0.001$ \\
\hline $\mathbf{N}$ & 52 & 27 & 43 & 30 & 23 & 28 & \\
\hline Mean & 56.2 & 56.0 & 56.5 & 56.5 & 52.6 & 56.1 & \\
\hline SD & 3.27 & 3.29 & 2.65 & 2.64 & 2.02 & 2.65 & \\
\hline Median & 57.0 & 56.0 & 57.0 & 57.0 & 52.0 & 56.5 & \\
\hline Upper limit & 60.0 & 60.0 & 60.0 & 60.0 & 56.0 & 60.0 & \\
\hline CV & $5.82 \%$ & $5.87 \%$ & $4.69 \%$ & $4.67 \%$ & $3.83 \%$ & $4.72 \%$ & \\
\hline Grade 3.5 & & & & & & & $<0.001$ \\
\hline $\mathbf{N}$ & 58 & 54 & 41 & 53 & 24 & 38 & \\
\hline Mean & 65.7 & 65.8 & 64.5 & 66.1 & 60.0 & 65.4 & \\
\hline SD & 2.29 & 2.82 & 2.74 & 3.12 & 1.63 & 2.83 & \\
\hline Median & 66.0 & 66.0 & 64.0 & 66.0 & 60.0 & 65.0 & \\
\hline Upper limit & 70.0 & 70.0 & 70.0 & 70.0 & 63.0 & 70.0 & \\
\hline CV & $3.49 \%$ & $4.29 \%$ & $4.24 \%$ & $4.72 \%$ & $2.71 \%$ & $4.32 \%$ & \\
\hline Grade 4 & & & & & & & $<0.001$ \\
\hline $\mathbf{N}$ & 23 & 29 & 13 & 22 & 26 & 31 & \\
\hline Mean & 73.8 & 74.3 & 74.9 & 74.0 & 66.0 & 75.0 & \\
\hline SD & 2.27 & 2.95 & 3.38 & 3.99 & 1.48 & 3.62 & \\
\hline Median & 74.0 & 73.0 & 74.0 & 73.0 & 66.0 & 75.0 & \\
\hline Upper limit & 80.0 & 80.0 & 80.0 & 80.0 & 68.0 & 80.0 & \\
\hline CV & $3.07 \%$ & $3.97 \%$ & $3.38 \%$ & $3.99 \%$ & $2.25 \%$ & $3.61 \%$ & \\
\hline Grade 4.5 & & & & & & & $<0.001$ \\
\hline $\mathbf{N}$ & 7 & 5 & 4 & 3 & 15 & 10 & \\
\hline Mean & 85.1 & 82.6 & 83.3 & 82.0 & 71.0 & 84.2 & \\
\hline SD & 1.77 & 1.82 & 2.22 & 1.73 & 1.93 & 2.66 & \\
\hline Median & 86.0 & 82.0 & 83.0 & 81.0 & 71.0 & 84.5 & \\
\hline Upper limit & 87.0 & 85.0 & 86.0 & 84.0 & 74.0 & 88.0 & \\
\hline CV & $2.08 \%$ & $1.20 \%$ & $2.66 \%$ & $2.11 \%$ & $2.71 \%$ & 3.16 & \\
\hline
\end{tabular}

* Kruskal-Wallis one-way analysis of variance (for $\mathrm{P}<0.05$, variances are significantly different for years of the study)

Table 5: Analysis of correlation between score on pharmacology exam and criteria used for selection of candidates for Pharmacy

\begin{tabular}{|l|c|c|c|c|c|c|}
\hline \multirow{2}{*}{ Admission Exam } & \multicolumn{7}{|c|}{ Pharmacology Exam } \\
\cline { 2 - 7 } & 2009 & 2010 & 2011 & 2012 & 2013 & 2014 \\
\hline Total scoring & $0.286^{*}$ & 0.182 & 0.066 & 0.205 & $0.401^{*}$ & $0.195^{*}$ \\
\hline Biology & 0.175 & 0.009 & -0.067 & 0.112 & $0.258^{*}$ & $0.242^{*}$ \\
\hline Chemistry & $0.234^{*}$ & $0.247^{*}$ & 0.129 & 0.038 & $0.345^{*}$ & 0.105 \\
\hline Mathematics & ---- & ---- & ---- & ---- & $-\cdots$ & 0.137 \\
\hline
\end{tabular}


higher compared to the remaining years of the study) and the mean item easiness was over 0.59 (no significant differences). Discriminatory capacity may be increased by a detailed analysis of particular questions comprising the pool of exam questions. This kind of assessment provides very useful information on an exam group and it also constitutes a foundation for evaluation and development of a high-quality database of exam questions. Questions with optimum easiness and sufficient differentiation parameters have a major impact on test sensitivity and they should constitute the core of the pool of exam questions and this is what should be pursued in the next years. The development of a proper database of exam questions is a long-lasting process and database resources need to be successively updated due to the process of "ageing" of exam questions. This process consists in an increase of easiness and decrease of differentiation power in the subsequent editions comprising the database. ${ }^{29}$

Since multistage MCQ exams are not standardized and normalized, the problem of reliability and comparability of students' grades in the subsequent years arises. The requirement of objectivity in assessment of students' achievements forces us to ask a question whether the system of converting scores into grades in the subsequent exam editions ensures a fair and comparable assessment of the same competences. Grades for the Pharmacology course are assigned exclusively on the basis of the results of the final exam (the so called summative assessment). According to the classification by Susan Brookhart, ${ }^{30}$ it can be assumed that it is meeting exam requirements ("outcome-based assessment") and not taking into consideration the effort made by students during the course ("effort-based assessment") that constitutes the only measurement of the outcomes of education in pharmacology. The above measurement is compliant with the idea of analytical assessment that is a three-stage process, comprising the following: determination of curricular requirements (stated in the standards of education), determination of standards of requirements (concluding based on the measurement results, e.g. using a test), and development of a student achievement scale (operationalization of a grading scale using requirements and standards). The performance standards are applicable in the case of the pharmacology exam, since no standardization of a test was performed with a selected sample in order to establish an empirical standard. With reference to this particular MCQ exam, from the practical point of view, it is most important to determine a quantitative standard, i.e. the smallest number of points obtained on the exam that confirms that a student met the requirements of a particular level. ${ }^{31}$ However, the a priori quantitative standard for phar- macology exams underwent a posteriori revision after receiving the test results. The analysis of the required score thresholds for MCQ exams demonstrated that the "passed/failed" cut-off point was always at the same level. With reference to the remaining score thresholds for the school grading scale $(3,3.5,4$, and 4.5$)$, it was found that in the case of the most difficult exam from those studied here (the 2013 year), score requirements for particular grades were significantly lower compared to the MCQ exams in the remaining years. The differences were particularly visible for grades over 3 . It needs to be emphasised that both the variability coefficient and interquartile range for the 2013 exam was not significantly different from those established for the remaining exams. A small number of persons with the "very good" grade were also an important finding with reference to the analysis of scores required for particular grades.

The determination of measurement validity that answers the question: "what is measured?" is also essential for the development of quality of assessment tools. Validity should be here understood as the degree of consistency to which a measurement tool measures what it is supposed to measure. Therefore, it is the usefulness of a particular test for assessment of a certain set of features and qualities of a candidate..$^{32}$ If a selected method de facto checks the ability of a candidate to adjust to an assessment tool (literally "What Do They Want Me To Say?"), then the assessment is not focused on features we would like to evaluate. ${ }^{33}$ There is no precise method to measure validity, only its indirect evaluation is possible and it usually consists in using one out of three ideas used for establishing measurement validity: content,${ }^{34}$ empirical, ${ }^{35}$ and construct validity. ${ }^{36,22}$ analysed the validity of PCAT and showed that a number of assessment strategies can be used: content, internal structure, concurrent, and predictive validity. One important type of validity is content validity - the degree of correspondence between the contents of the test and the logical and curricular domains intended to be measured.2. In the case of the pharmacology exam, the consistency of the contents of exam questions and standards of education for this particular course are important with reference to curricular validity. Validation of this parameter requires analysis of test content outlines. Internal structure validity involves the degree to which psychometric relationships among components within a test are consistent with the intended meaning of scores for those components. ${ }^{22}$ In order to assess the internal structure validity, it is necessary to distinguish subtests that shall represent questions from certain categories compliant with the taxonomy of goals stated in the test content outlines and then establish intercorellations between 
subtests. The analysis of validity with the use of the correlation between the scores obtained on one exam and the scores obtained by the same students on a different test is referred to as concurrent validity. ${ }^{13,15,16}$ Still, the predictive validity refers to the assessment of the prognostic capacity of exam scores to predict future careers of candidates, e.g. achievement of professional success during the university education or the future professional status of a graduate..$^{4-7,9,13,16,37-41}$ Due to the obvious reasons, the term "concurrent and predictive validity" is impossible in the case of pharmacology exams. There are no results of a simultaneously conducted assessment and there are no data on future careers of students ${ }^{13}$ and graduates ${ }^{16}$ with reference to their professional activity after graduation from pharmacy school.

The analysis of correlations between the results of the pharmacology exam and admission exam showed no systematically occurring correlations between those variables. It is symptomatic that only the 2013 exam results were significantly correlated with the two selection criteria used in the admission process for Pharmacy (Pearson's $r$ for biology and chemistry amounted to 0.258 and 0.345 , respectively). With reference to the analysis of score requirements for particular grades, the 2013 exam was the only one that differed from the established score thresholds. This exam was also most difficult (index of test difficulty of 0.59 and average discriminating power of 0.234 ). Considering the above findings, the outcomes of the 2013 exam should provide the basis for future efforts to improve the Pharmacology exam. Assuming that the matura exam in chemistry and biology at the extended level is standardized and normalized by the Central Examinations Board, which supervises the national exam, the results of the admission exam should be treated as a very important predictor. ${ }^{42}$ The literature shows that good results of predictive analyses may be achieved for the output variable, namely for the academic performance in the first-year of pharmacy school. ${ }^{4,5}$ Therefore, prospective studies on developing multiple regression model for making predictions should be based on several factors, including also the results of the pharmacology exam.

\section{CONCLUSION}

Conclusion states that the above findings concerning the reliability, sensitivity, objectivity and validity of the Pharmacology Exams conducted at the Faculty of Pharmacy, MUW demonstrated that, with all methodological limitations of retrospective studies, the scores of these exams might constitute a good output variable for a predictive assessment. However, continuous evalu- ation and improvement of the exam test are necessary, particularly with reference to the assessment of measurement validity. Moreover, data on future careers of students and graduates should be consistently collected for the needs of a predictive analysis conducted with the use of a regression model including various explanatory variables.

\section{ACKNOWLEDGMENTS}

Acknowledgements for Henryk Rebandel, PhD, longterm chairperson of the Medical University of Warsaw Admission Board, for help in preparation of data for analysis.

\section{COMPETING INTERESTS}

The authors declare that they have no competing interests.

\section{STUDY FUNDING}

This work was supported by the Medical University of Warsaw under number NZD/PM41/14 (Young Investigator Grant).

\section{REFERENCES}

1. Janczukowicz J. Medical education in Poland. Med Teach. 2013; 35(7): 537-43.

2. Bartkowiak LE. Professional views of pharmacy faculty graduates. Wiadomosci lekarskie 2006; 59(5-6): 303-10.

3. Wolkowitz AA. Multiple attempts on a nursing admissions examination: Effects on the total score. Journal of Nursing Education 2011; 50(9): 493-501.

4. Meagher DG, Lin A, Stellato CP. A predictive validity study of the Pharmacy College Admission Test. Am J Pharm Educ. 2006; 70(3): 53.

5. Meagher DG, Lin A, Perez CD. Predicting pharmacy students' performance from PCAT scores: a further analysis of predictive validity study data. Am J Pharm Educ. 2007; 71(5): 101.

6. Kuncel NR, Crede M, Thomas LL, Klieger DM, Seiler SN, Woo SE. A metaanalysis of the validity of the Pharmacy College Admission Test (PCAT) and grade predictors of pharmacy student performance. Am J Pharm Educ. 2005; 69(3): 339-47.

7. Kidd RS, Latif DA. Traditional and novel predictors of classroom and clerkship success of pharmacy students. Am J Pharm Educ. 2003; 67(4): 109.

8. Houglum JE, Aparasu RR, Delfinis TM. Predictors of academic success and failure in a pharmacy professional program. Am J Pharm Educ. 2005; 69(3): 43.

9. Meagher DG, Pan T, Perez CD. Predicting performance in the first-year of pharmacy school. Am J Pharm Educ. 2011; 75(5): 81.

10. Renzi SE, Krzeminski MA, Sauberan MM, Brazeau DA, Brazeau GA. Prepharmacy years in college and academic performance in a professional program. Am J Pharm Educ. 2007; 71(4): 69.

11. Hardinger KL, Schauner S, Graham M, Garavalia L. Admission predictors of academic dismissal for provisional and traditionally admitted students. Currents in Pharmacy Teaching and Learning 2013; 5(1): 33-8.

12. Myers TL, DeHart RM, Vuk J, Zoran B. Prior degree status of student pharmacists: Is there an association with first-year pharmacy school academic performance? Currents in Pharmacy Teaching and Learning 2013; 5(5): 490-3.

13. Allen DD, Bond CA. Pre-pharmacy predictors of success in pharmacy school: grade point averages, pharmacy college admissions test, communication abilities, and critical thinking skills. Pharmacotherapy 2001; 21(7): 842-9. 
14. Cameron AJ, Mackeigan LD. Development and pilot testing of a multiple mini-interview for admission to a pharmacy degree program. Am J Pharm Educ. 2012; 76(1): 10.

15. Cox WC, Persky A, Blalock SJ. Correlation of the Health Sciences Reasoning Test with student admission variables. Am J Pharm Educ. 2013; 77(6): 118

16. McCall KL, MacLaughlin EJ, Fike DS, Ruiz B. Preadmission predictors of PharmD graduates' performance on the NAPLEX. Am J Pharm Educ. 2007; 71(1): 5.

17. Atkinson J, Rombaut B. The PHARMINE study on the impact of the European Union directive on sectoral professions and of the Bologna declaration on pharmacy education in Europe. Pharmacy practice 2011; 9(4): 188-94.

18. Wilson S, Tordoff A, Beckett G. Pharmacy professionalism: A systematic analysis of contemporary literature (1998-2009). Pharmacy Education 2010; 10(1): 27-31.

19. Feldt LS. A test of hypothesis that Cronbachs alpha or Kuder-Richardson coefficent 20 is same for 2 tests. Psychometrika. 1969; 34(3): 363-73.

20. Guttman L. A basis for analyzing test-retest reliability. Psychometrika 1945; 10(4): 255-82.

21. Cohen J. Statistical power analysis for the behavioral sciences. 2nd ed. Hillsdale, NJ: Lawrence Erlbaum Associates; 1988.

22. Meagher DG, Pan T, Wegner R, Olson AT, Overgaard SL, Mehle JJ. PCAT Reliability and Validity. 3rd ed. San Antonio: Pearson Executive Office; 2012.

23. Streiner DL. Starting at the beginning: an introduction to coefficient alpha and internal consistency. Journal of personality assessment 2003; 80(1): 99-103.

24. Guilford JP. Psychometric methods. 2nd ed. New York: McGraw-Hill; 1954.

25. Kolen MJ, Hanson BA, Brennan RL. Conditional Standard Errors of Measurement for Scale Scores. Journal of Educational Measurement 1992; 29(4): 285-307.

26. Baker FB. Computer technology in test construction and processing. In: Linn RL, editor. Educational Measurement. $3^{\text {rd }}$ ed. New York: ACE; 1989.

27. Downing SM. The effects of violating standard item writing principles on tests and students: the consequences of using flawed test items on achievement examinations in medical education. Advances in health sciences education : theory and practice $2005 ; 10(2): 133-43$.
28. Boland RJ, Lester NA, Williams E. Writing Multiple-Choice Questions. Academic Psychiatry 2010; 34(4): 310-6.

29. Case SM, Swanson DB. Constructing Written Test Questions For the Basic and Clinical Sciences. 3rd ed: National Board of Medical Examiners; 2002.

30. Brookhart SM. Teachers' grading practices: Meaning and values. Journal of Educational Measurement. 1993; 30(2): 123-42.

31. Ben-David MF. AMEE Guide No. 18: Standard setting in student assessment. Medical Teacher 2000; 22(2): 120-30.

32. Goodwin LD. Changing conceptions of measurement validity: an update on the new standards. The Journal of nursing education 2002; 41(3): 100-6.

33. White J, Brownell K, Lemay JF, Lockyer JM. "What do they want me to say?" The hidden curriculum at work in the medical school selection process: a qualitative study. BMC Medical Education 2012; 12(1):17.

34. Ebel RL. Must all tests be valid? American Psychologist 1961; 16(10): 640.

35. Reezigt GJ, Guldemond H, Creemers BP. Empirical validity for a comprehensive model on educational effectiveness. School effectiveness and school improvement. 1999; 10(2): 193-216.

36. Cronbach LJ, Meehl PE. Construct validity in psychological tests. Psychological bulletin 1955; 52(4): 281.

37. Kuncel NR, Hezlett SA. Assessment. Standardized tests predict graduate students' success. Science 2007; 315(5815): 1080-1.

38. Hardigan PC, Lai LL, Arneson D, Robeson A. Significance of academic merit, test scores, interviews and the admissions process: A case study. AAm J Pharm Educ. 2001; 65(1): 40-4.

39. Lobb WB, Wilkin NE, McCaffrey DJ, Wilson MC, Bentley JP. The predictive utility of nontraditional test scores for first-year pharmacy student academic performance. Am J Pharm Educ. 2006; 70(6): 128.

40. Cunny KA, Perri M. Historical-perspective on undergraduate pharmacy student admissions - the PCAT. AAm J Pharm Educ. 1990; 54(1): 1-6.

41. Thomas MC, Draugalis JR. Utility of the Pharmacy College Admission Test (PCAT): Implications for Admissions Committees. Am J Pharm Educ. 2002; 66(1): 47-51.

42. Mercer A, Puddey IB. Admission selection criteria as predictors of outcomes in an undergraduate medical course: a prospective study. Med Teach. 2011; 33(12): 997-1004. 